\title{
Difusão lexical e variação fonológica: o fator semântico
}

\section{Evelyne Dogliani Madureira Universidade Federal de Minas Gerais}

\section{Abstract}

This article presents evidence for the Lexical Diffusion model in the vocalization of $[\mathrm{lh}]$ in the speech of informants from Belo Horizonte. A set of words in which the vocalization seems to be introduced in the middle-class group is restricted to informal speech styles. Moreover, as far as semantics, is concerned the actuation of Lexical Diffusion is focused regardless of variation, this being seen as an ulterior hypothetical step in the process. This enables us to distinguish social groups internal and external changes in terms of the implementation of lexical diffusion. 


\section{1 - INTRODUÇÃO}

$\mathrm{E}$ ste artigo trata do modelo da Difusão Lexical na análise da vocalização da lateral palatal. ${ }^{1}$ A literatura descreve o fenômeno, no Brasil, como um processo que evidencia variação regional e social. ${ }^{2} \mathrm{O}$ mesmo pode ser expressado da seguinte maneira: $[\lambda],\left[1^{y}\right],[1]$ e [y ] são os fones que realizam variavelmente o fonema $/ \lambda /$. Em termos da Teoria da Variação, diremos que $[\lambda]$, [1 $\left.{ }^{y}\right],[1]$ e [ y ] são as variantes lingüísticas que realizam a variável (lh). Tomando como exemplo a palavra mulher e observando as várias pronúncias que esse item recebe no português do Brasil, diremos que a variável (lh) se realiza como [ y ] em [ muy'e ]; como [1] em [ mu'le ] e como [ $\lambda$ ] ou [ $1^{\mathrm{y}}$ ] em [ mu' $\lambda \varepsilon$ h ] ou [ mu'l y $\varepsilon$ h ], representando as duas últimas a pronúncia padrão. A pesquisa, circunscrita à região de Belo Horizonte, através de uma pequena amostra, descreve apenas as variantes $\left[1^{\mathrm{y}}\right]$ ou $[\lambda]$ e $[y] .^{3}$

A variação de [ $1^{y}$ ] e [y ] responde, em Belo Horizonte, a fatores sociais, sendo [ y ] característica do grupo social mais baixo. Não foi, todavia, a mera descrição desse processo que guiou a pesquisa, que teve por objetivo central a busca de explicação de um subfenômeno mais específico - a variação de [ $\lambda$ ] e [ y ] no grupo social mais alto, variação que, nesse caso, parecia associada a outro tipo de variação - a de contextos de fala, que pode ser descrita da seguinte maneira: os falantes do grupo social mais alto usam a variante [ $\lambda$ ], em contextos de fala referenciais, mas essa variante deixa de ser categórica para alguns deles quando se trata de contexto de fala afetivo. Essa variação evidencia-se quando observamos a fala de um professor que, durante a aula, para referir-se, por exemplo, a distinções culturais entre os sexos (contexto de fala referencial), refere-se à mulher com a pronúncia [ mu’ $\lambda \varepsilon h$ ] e, que, posterior- 
mente, para referir-se a um desafeto (contexto de fala afetivo) diz: [ muy' $\varepsilon$ ]. Dessa observação resultou a pergunta que guiou a pesquisa: se é verdade que o contexto de fala afetivo pode evidenciar realizações lingüísticas distintas das evidenciadas em contextos de fala referenciais, uma vez que a forma evidenciada naquele contexto é exatamente a realização lingüística propagada pelo grupo social mais baixo. Uma segunda ponderação emergia: se uma análise desses fatos revelar algum grau de sistematicidade, é possível que esse processo de variação tenha um prolongamento no nível lexical, através dos graus de afetividade de que se impregnam os itens lexicais nos vários contextos em que se atualizam. Tais considerações embasaram a seguinte hipótese de trabalho: "Como a regra de vocalização se realiza com mais freqüência nos grupos mais baixos da escala social - sendo, portanto, estigmatizada - sua propagação, se houver, para um grupo social superior se dará através de expressões ou itens caracterizadamente portadores de mensagens afetivas, basicamente aqueles itens de conotação pejorativa." A análise dos dados permitiu a manutenção dessa hipótese, tendo sido evidenciados dois itens responsáveis pelo percentual de vocalização no grupo socialmente mais favorecido. São eles: trabalhar e velho, itens passíveis de atribuição de conotação pejorativa. (ver seção 3).

\section{2 - METODOLOGIA DA PESQUISA}

A pesquisa descrita em 1 desenvolveu-se com base na metodologia proposta pela Teoria da Variação, desde a coleta de dados até a sua análise. Os informantes, em número de 8 , foram classificados por grupo social: grupo social mais favorecido (doravante G1) e grupo social menos favorecido (doravante, G2), por sexo, idade (jovens e adultos) e por escolaridade, e submetidos a duas entrevistas com intervalo de um ano. Tal classificação visava a uma análise nãoestrutural do fenômeno. Quanto à análise estrutural, foram considerados os parâmetros: segmentos contíguos à variável e tonicidade. A esses foi acrescentado o parâmetro item lexical. 
Os dados que serviram de base à análise quantitativa foram extraídos das entrevistas já mencionadas. Para a análise qualitativa acrescentaram-se às entrevistas alguns testes: um teste de descrição de gravuras que mostravam objetos representados por palavras que contêm a lateral palatal (esse teste foi aplicado com o mero objetivo de forçar a ocorrência da variável cuja presença na língua é bastante escassa) e dois testes de percepção lingüística. O primeiro foi aplicado aos mesmos informantes da entrevista, no intuito de que expressassem o estigma (quando houvesse) à variante [y ]. Os informantes foram expostos a uma série de enunciados previamente gravados por indivíduos a cuja identidade eles não tinham acesso. Constavam dos enunciados palavras contendo a lateral palatal cuja pronúncia era apresentada ora na forma padrão, ora na forma nãopadrão. Foi pedido aos informantes que atribuíssem uma profissão (dentre as profissões constantes de uma lista que lhes foi apresentada) aos emissores dos enunciados que ouviam. Foi também pedido que eles justificassem a resposta dada.

O segundo teste foi aplicado a um grupo de professores universitários e caracterizou-se como segue: os informantes foram induzidos a usar substantivos coletivos nos quais o sufixo composto -alhada alterna com outros sufixos que expressam quantidade, tais como -eiro; -aria, como em pratalhada e prataria, por exemplo. A suposição subjacente à aplicação desse teste era a de que o sufixo -alhada seria preterido aos demais, em função da conotação pejorativa que carreia, salvo naquelas situações em que os falantes quisessem ser pejorativos. ${ }^{4} \mathrm{O}$ objetivo era testar o comportamento da variável nesse item claramente portador de conotação pejorativa.

\section{3 - A ANÁLISE}

\subsection{A análise quantitativa - fatores estruturais: o item lexical como fator de implementação}

Foram considerados os seguintes parâmetros estruturais: contexto fonético da variável (traços da vogal precedente e seguinte) 
e tonicidade. Uma análise qualitativa da atuação desses fatores levou à inclusão de um outro parâmetro na análise - o item lexical. Resumo, a título de ilustração, a evolução da análise a partir da consideração de um dos fatores.

O fator segmento precedente - A análise quantitativa evidenciou, num primeiro momento, que a realização de [y ] é favorecida pelas vogais posteriores como segmento precedente. (Tab. 3.1). ${ }^{5}$

\begin{tabular}{|l|c|c|c|c|}
\hline & $\begin{array}{c}\text { Total de } \\
\text { dados }\end{array}$ & $\begin{array}{c}\text { Total de } \\
\text { aplicação }\end{array}$ & $\begin{array}{c}\text { \% de } \\
\text { aplicação }\end{array}$ & $\mathrm{X}^{2}$ \\
\hline Anteriores & 277 & 18 & 07 & 19.293 \\
\hline Posteriores & 457 & 84 & 18 & \\
\hline Total & 734 & 103 & 14 & \\
\hline
\end{tabular}

Tabela 3.1: Segmento precedente: efeito das vogais anteriores e posteriores

O resultado dessa tabela contraria as tendências dos processos fonológicos, isto é, a vocalização de [ $\lambda$ ] deveria encontrar favorecimento entre as vogais anteriores. Considerou-se, então, que o favorecimento das posteriores poderia estar evidenciando a interferência da vogal /a/ através do traço que a distingue das outras vogais posteriores, o traço [-arredondado]. De fato, a oposição entre vogais pelo traço [+ arredondado] mostrou o favorecimento das vogais [-arredondadas]: ( $\left.X^{2} 26.323\right)$. Esse favorecimento não se manteve, entretanto, quando o mesmo cálculo foi repetido com a exclusão da vogal /a/. (Tab. 3.2). 


\begin{tabular}{|l|c|c|c|c|}
\hline & $\begin{array}{c}\text { Total de } \\
\text { dados }\end{array}$ & $\begin{array}{c}\text { Total de } \\
\text { aplicação }\end{array}$ & $\begin{array}{c}\text { \% de } \\
\text { aplicação }\end{array}$ & $\mathrm{X}^{2}$ \\
\hline Anteriores & 277 & 19 & 07 & 0.534 \\
\hline Posteriores & 189 & 15 & 08 & \\
\hline
\end{tabular}

Tabela 3.2: Segmento precedente: efeito das vogais anteriores e posteriores com exclusão de /a/

Essa tabela permite concluir que não é pelos seus traços [+posterior] e [-arredondado] que a vogal /a/ está favorecendo a aplicação da regra em estudo. O seu favorecimento se mantém, sem que tenhamos, para tanto, uma explicação fonética.

Paralelamente, uma observação dos itens lexicais revelou que 93\% das ocorrências de /a/ como segmento precedente correspondiam ao item lexical trabalhar. A hipótese de que o verbo trabalhar fosse responsável pelos diferentes condicionamentos fonéticos evidenciados em várias tabelas, levou a novos cálculos dos quais o item trabalhar foi excluído. Sua exclusão neutralizou qualquer tipo de condicionamento fonético, permitindo manter a hipótese de que o verbo trabalhar favorece a aplicação da regra de vocalização. (Tab. 3.3).

\begin{tabular}{|l|c|c|c|c|}
\hline & $\begin{array}{c}\text { Total de } \\
\text { dados }\end{array}$ & $\begin{array}{c}\text { Total de } \\
\text { aplicação }\end{array}$ & $\begin{array}{c}\text { \% de } \\
\text { aplicação }\end{array}$ & $\mathrm{X}^{2}$ \\
\hline trabalhar & 248 & 66 & 27 & 48.39 \\
\hline demais dados & 486 & 37 & 08 & \\
\hline Total & 734 & 103 & 14 & \\
\hline
\end{tabular}

Tabela 3.3: segmento precedente: oposição entre trabalhar e o conjunto dos dados restantes 
Apenas uma das variáveis estruturais revelou-se, portanto, favorecedora em relação à vocalização da lateral palatal - o fator item lexical. A atuação desse parâmetro permitiu que os itens lexicais fossem divididos em blocos com base nos seus percentuais de vocalização. (Tab. 3.4).

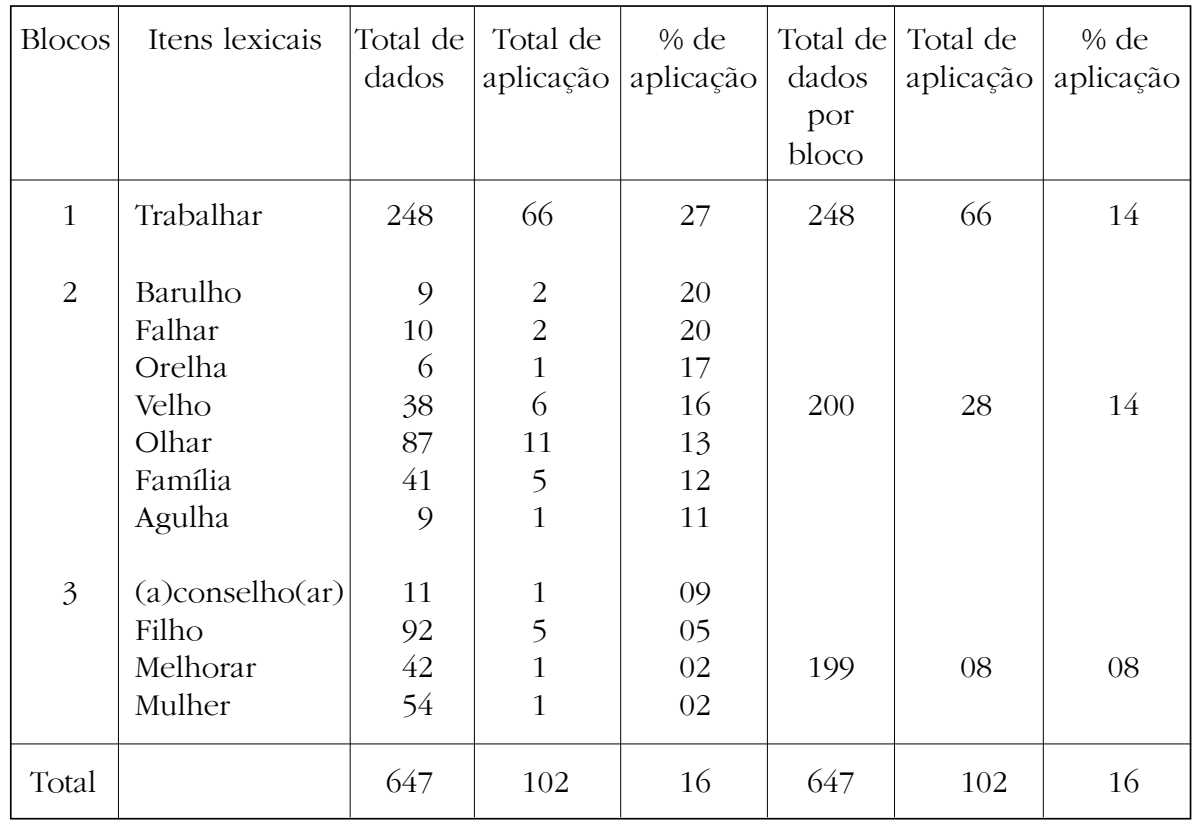

Tabela 3.4: Distribuição do léxico em blocos de freqüência

Essa distribuição dos itens lexicais foi confirmada quando se cruzaram os fatores não-estruturais analisados com o fator item lexical. São os seguintes os percentuais de vocalização por bloco (Tab. 3.5): 


\begin{tabular}{|c|rr|r|}
\hline Blocos & \multicolumn{2}{|c|}{$\begin{array}{l}\text { \% de vocalização } \\
\text { por grupo social }\end{array}$} & \multicolumn{1}{|c|}{$\mathrm{X}^{2}$} \\
\hline & $\mathrm{G} 1$ & $\mathrm{G} 2$ & $\mathrm{G} 2$ \\
1 & 6 & 43 & 48.122 \\
2 & 4 & 26 & 20.294 \\
3 & 3 & 6 & 0.556 \\
\hline
\end{tabular}

Tabela 3.5. Efeito do parâmetro grupo social por blocos de dados.

Como se vê, há um decréscimo das diferenças observáveis entre os dois grupos sociais, quando caminhamos do primeiro para o terceiro bloco. Observe-se que no terceiro bloco de itens a atuação do fator grupo social é neutra.

No G2, praticamente todos os itens lexicais apresentam vocalização, enquanto no G1 apenas quatro itens foram sensíveis ao fenômeno. São eles: trabalhar, velho, olhar e filho.

A análise não-estrutural apresentou, portanto, indícios de que o processo de difusão lexical se evidencia nos dois grupos sociais observados. Esperava-se, então, que os itens que apresentaram vocalização no G1 fossem exatamente aqueles que apresentaram os maiores percentuais no G2. De fato, dois itens se destacam por seus percentuais de vocalização nos dois grupos pesquisados. O primeiro é o item trabalhar, cujo percentual de vocalização é $6 \%$ no G1 e $43 \%$ no G2. O segundo é o item velho que apresenta os seguintes resultados: 10\% no G1 e 37\% no G2. Além do percentual de vocalização superior aos demais itens, outro fator que destaca esses dois itens é a possibilidade de se lhes atribuir conotação pejorativa.

Os resultados da análise quantitativa foram suficientes indícios de que a variação em estudo se dá por difusão lexical. Restava-nos, nesse ponto, investigar a segunda parte da hipótese formulada, qual seja, a propagação da vocalização da lateral palatal, se houver, se dará através de itens portadores de mensagens afetivas, basicamente aqueles de conotação pejorativa. 


\subsection{A análise qualitativa - o significado do item como fator de implementação}

Como dissemos acima os dois itens que se destacaram na análise quantitativa - trabalhar e velho são passíveis de atribuição de conotação pejorativa.

Trabalhar - A conotação pejorativa desse item pode ser observada naquelas situações em que o uso está relacionado à oposição lazer/trabalho. Lazer tem conotação positiva; trabalho tem conotação negativa. Essa constatação não é subjetiva. A associação encontrada na Bíblia entre trabalho e castigo, a origem do item trabalho (do latim tripalium = instrumento de tortura) são apenas algumas evidências da conotação negativa desse item.

Velho - A conotação pejorativa desse item evidencia-se pelo seu uso em determinadas situações e pela sua substituição em outras. Esse item parece ser evitado quando queremos expressar respeito, porque na nossa sociedade a velhice não é um estado pelo qual ansiamos. Chamar alguém de velho é atribuir-lhe uma característica indesejável. ${ }^{6}$ Além disso e excetuadas as circunstâncias em que o item é usado para expressar afetividade, o uso social do item velho está associado ao status de quem é portador dessa característica.

Vejamos o que os testes de percepção lingüística apontaram acerca da conotação dos itens lexicais. No primeiro teste de percepção lingüística, os informantes tenderam a atribuir profissões associadas a baixa renda aos emissores de enunciados contendo estruturas (sintáticas ou fonológicas) não-padrão. Dentre as variáveis fonológicas não-padrão foi apontada a vocalização da lateral palatal. As observações relevantes dizem respeito a um dos itens assinalados pela análise quantitativa - $\mathrm{O}$ item velho -, por se coadunarem com as nossas considerações sobre a conotação de velho. Ex.: a vocalização de velho foi menos notada no enunciado

"Ó Lu, tem um véio no portão pedindo esmola..."

do que no enunciado 
"Gente, os lugar(es) já tão marcado: os mais véio fica atrás, os outro na frente..."

Além disso, quando a vocalização não foi notada, o uso do item velho foi apontado como inconveniente no segundo enunciado, principalmente. Isso sugere que um velho pedindo esmola pode ser chamado de velho; um outro bem vestido, será provavelmente tratado de forma mais respeitosa. ${ }^{7}$

Quanto ao segundo teste de percepção lingüística, os informantes confirmaram explicitamente a conotação pejorativa do sufixo -alhada, distinguiram espontaneamente situações de fala em que usariam esse sufixo das situações em que usariam outro como -aria ou -eiro e, quando exemplificaram a ocorrência de -alhada, (aí vem o dado relevante desse teste) fizeram-no usando de forma regular a variante $[y]$ e não $[\lambda]$, evidenciando na análise geral um caso de reestruturação lexical, em um grupo social compatível com o dos informantes do G1.

\section{4 - QUESTÕES TEÓRICAS}

A análise apresentada em 3 envolve questões teóricas tanto no que diz respeito à evidenciação do item lexical como fator implementador de variação e mudança lingüística, como no que concerne aos fatores responsáveis pela atuação do modelo da difusão lexical. O primeiro aspecto diz respeito à famigerada polêmica entre Neogramáticos e Difusionistas. O segundo pressupõe uma hierarquização dos fatores apontados pela literatura.

O modelo da difusão lexical postula que a mudança lingüística é lexicalmente gradual e foneticamente abrupta, contrariamente ao que apregoavam os Neogramáticos cujos trabalhos permitiram que a sistematicidade das leis fonéticas evidenciada pela lingüistica diacrônica se fixasse como princípio explicativo da mudança lingüística. O modelo da Difusão Lexical tem seus primeiros portavozes nos dialetologistas, que, trabalhando com as línguas vivas, 
questionaram a regularidade das leis fonéticas. Esse questionamento só foi submetido a reconsiderações mais profundas no período em que se desenvolveram os trabalhos sociolingüísticos, especificamente alguns realizados por Chen e Wang sobre o chinês. Em publicação de 1975, os dois autores apresentam evidências de que a mudança sonora não é regular, caracterizando-se como lexicalmente gradual e foneticamente abrupta. Difusão Lexical é o nome dado a essa nova concepção da mudança, cuja produtividade tem sido alvo de discussões freqüientes no âmbito da pesquisa da variação e mudança lingüística. (cf. Labov 1981 e 1994) ${ }^{8}$

Se, por um lado, as evidências de produtividade do modelo de Difusão Lexical se acumulam, ${ }^{9}$ por outro, suas condições de aplicação são, ainda, bastante nebulosas. Todos os trabalhos que o evidenciam proclamam implícita ou explicitamente a necessidade de se explicar como (ou quando ou por quê) determinados itens lexicais realizam-se com determinada forma (fonológica ou sintática) em detrimento de outros. A literatura destaca alguns fatores, tais como freqüência, estilo de fala, status do item. Sugerimos aqui que fatores relacionados ao significado podem estar atuando.

O fato de os itens que apresentam maior percentual de vocalização no G1 serem passíveis de atribuição de conotação pejorativa, aliado aos resultados apresentados pelo teste realizado com o sufixo -alhada, permitiu que a hipótese de relação entre conotação afetiva (pejorativa, no caso dos nossos dados) e mudança lingüística fosse mantida. Essa hipótese situa a análise de um fator impulsionador do modelo da difusão lexical na interface de dois componentes da gramática, o fonológico e o semântico (e na interface deste com o pragmático). Envolve, além disso, considerações relativas ao conceito de variantes lingüísticas, cujo estabelecimento pela Teoria da Variação se pauta por uma semântica das condições de verdade.

Como vimos, no caso dos dados discutidos em 3, o fato de atribuirmos conotações variáveis aos itens analisados não altera o seu sentido denotativo. Ou seja, com conotação negativa ou positiva, 
o item trabalhar expressa sempre "atividade coordenada, de caráter físico e/ou intelectual, necessária à realização de qualquer tarefa”. Mas, se observarmos um item como palhaço (que não integra o corpus em análise), observamos que sua realização com ou sem vocalização, em um grupo social compatível com o nosso G1, não remete a um mesmo sentido. Esse grupo social vocaliza a lateral palatal contida no item palhaço (quando o faz) nos contextos de fala em que o mesmo tem o sentido de "indivíduo que diz ou faz tolices" e não, quando o item tem o sentido de "elemento integrante do conjunto dos personagens circenses". Portanto, deparamo-nos, com um caso de variação lingüística em trabalhar, mas não, em palhaço. Entretanto, gostaríamos, de relacionar os dois fenômenos, no âmbito da análise da variação lingüística, já que a variação observável nos dois itens apresenta um fator comum, o de evidenciar uma alteração qualquer de sentido. A observação assistemática de dois outros itens (pelos falantes de um grupo social compatível com o G1, em Belo Horizonte) pode ser útil para orientar a nossa reflexão. Trata-se dos itens velho (coincidentemente, um dos itens que se destacaram em nossa análise) e palha.

O item velho - usado coloquialmente como cumprimento tem sido freqüentemente realizado com a variante [y ] em ocorrências como: "Eai, velho, tudo beleza?" O outro - o item palha, quando usado para significar "atividade fácil e sem importância" é pronunciado com a variante [ y ]. Ex.: "Ah, isso não conta; isso é palba." Esses dois itens requerem provavelmente análises distintas no que se refere a sua pronúncia. A ocorrência de variação [ $\lambda$ ] e [ y ], nos exemplos dados acima, é provavelmente mais freqüente no item velho do que no item palha. Nesse último, aliás, uma avaliação puramente intuitiva sugere que ele se realiza sistematicamente com [ y ]. A análise da história dos dois itens permite-nos algumas especulações que caracterizarão [ $\lambda$ ] e [ y ] como variantes de um mesmo fonema em velho e como fonemas distintos em palha.

O uso do primeiro como saudação expressa um segundo sentido do item fixado na língua, já de longa data, o que pode 
explicar a ocorrência do item com a variante $[\lambda]$, no grupo adulto, e com a variante [y ], no grupo jovem. Se assim for, poderemos atribuir a $[\lambda]$ e $[y]$ o rótulo de variantes condicionadas por faixa etária, conforme a definição de variante lingüística proposta pela teoria da variação. Já no caso do item palha, seu segundo sentido parece relativamente novo com emergência restrita ao grupo jovem. A variante vocalizada com a qual esse novo item se realiza apresentase, então, claramente como um fonema. Portanto no caso do item palha, não estamos diante de duas variantes, até o momento. Imaginemos, entretanto, como poderá ser a implementação do novo sentido de palha. São apenas duas as opções: ou não extrapola o âmbito da gíria e, por isso mesmo, tem vida efêmera, ou fixa-se no léxico. O primeiro caso é de pouco interesse para a nossa reflexão: a utilidade de sua análise limita-se à demonstração da relação formasentido. É o segundo, na verdade, que nos interessa. Ao fixar-se no léxico, essa nova forma [ 'pay e ] pode (ou não), em certos contextos sociais (provavelmente, no grupo socialmente mais favorecido), ser reconstruída pelo paradigma fonológico do seu primeiro sentido, na pronúncia padrão, com a pronúncia não-vocalizada da lateral palatal, instaurando-se, nesse momento, um processo de variação conforme definição da Teoria da Variação.

A hipótese subjacente ao que foi dito acima pode ser assim resumida: todo item lexical ao qual se pretende atribuir um novo sentido é passível de alteração em sua forma. Chamemos a esse item forma básica; àquele que veicula o novo sentido, forma derivada. Essa forma derivada pode, em momento posterior ao de sua instauração na língua, ser reanalisada (pelo grupo de falantes mais exposto à norma culta) pela forma fonológica de sua forma básica por atuação das normas do dialeto padrão. Nesse momento, estabelece-se um processo de variação fonológica (conforme definição da Teoria da Variação) que pode resultar (ou não) em mudança. Essa hipótese representa o ponto de intersecção de duas outras, quais sejam: toda variação fonológica tem sua origem na expansão do sentido de um item lexical, o que se realiza através de 
alteração na realização de um fonema, constituindo-se essa alteração em uma marca. Num segundo momento, outros itens adotam a marca daquele primeiro para veicular uma alteração de sentido qualquer. A variação fonológica, propriamente dita, ocorrerá num terceiro momento, se a marca realizada nos dois processos anteriores for sensível ou produtiva relativamente ao sistema fonológico da língua em que ocorre (cf. Oliveira, 1992 e nota 8). Essa hipótese pressupõe, portanto, que a variação fonológica, quando existe, expressa a fase de um processo cujo fator desencadeador é externo ao componente fonológico. Ela não é relevante na abordagem descritiva que caracteriza a Teoria da Variação. É relevante enquanto proposta de análise dos fatores que determinam a variação, via item lexical, fatores esses que requerem análise diacrônica. Além de pressupor o fator desencadeador da mudança no componente semântico, essa hipótese pressupõe um modelo semântico postulado como autônomo e projetável em outros componentes da gramática.

\section{5 - CONCLUSÃO}

Este artigo $^{10}$ apresentou, através da análise da vocalização da lateral palatal, em um grupo de informantes de Belo Horizonte, evidências de que a variação e a mudança lingüística se implementam por Difusão Lexical. Dentre os parâmetros estruturais considerados, o único a apresentar algum grau de favorecimento foi o fator item lexical, através de dois itens: trabalhar e velho.

No que diz respeito às condições de mudança nas realizações fonológicas dos itens, foi destacado o fator significado, cuja atuação foi delineada na interface dos componentes semântico e pragmático, na medida em que são evidenciados dois subfatores: alteração de sentido e contexto de fala (afetivo x referencial).

A análise dos dados associada à observação assistemática do comportamento de dois itens (velho e palha) que contêm a variável em estudo, no português contemporâneo de Belo Horizonte, 
permitiu um refinamento da hipótese inicialmente proposta, da seguinte maneira: a mudança fonológica tem por elemento desencadeador uma alteração de sentido que afeta um segmento de determinado item lexical, processo esse que pode ser seguido de variação, quando ocorre em contexto favorecedor, considerado o sistema da língua em foco.

As hipóteses aqui resumidas exigem refinamentos vários e estão sendo submetidas a análises (cf. Madureira, 1996) que têm por base processos de mudança fonológica e/ou sintática no português.

\section{NOTAS}

${ }^{1}$ A análise referida é descrita em Madureira (1987), trabalho orientado pelo prof. Marco Antônio de Oliveira a quem agradeço não só a orientação dada à época, como a disponibilidade demonstrada até o presente momento, para a discussão que a análise proposta engendra.

${ }^{2}$ A vocalização da lateral palatal caracteriza-se como fenômeno românico com manifestações diferenciadas nas línguas em que descrições diacrônicas o evidenciam. No francês, por exemplo, caracteriza-se como mudança completada entre o final do século passado e início deste, ao passo que, no português do Brasil, a menção ao fenômeno restringe-se, quando existe em compêndios de história da língua (anteriores ao desenvolvimento da sociolingüística), a observações sobre realizações não-padrão ou regionais. É abordado como variante social na pesquisa descrita neste artigo e, anteriormente, em Oliveira (1983).

${ }^{3}$ No que diz respeito à variante padrão os dados da pesquisa descrita neste artigo foram classificados de acordo com a variante que exibiam [ $\lambda$ ] ou [ $\left.1^{\text {y }}\right]$. Nem sempre foi fácil distinguir as duas, já que o material de que se dispunha para tanto era apenas o das gravações. A classificação requereu a aferição por parte do meu orientador, como também por parte de um especialista, o prof. César Reis, a quem agradeço pela colaboração. Para efeito de contagem, todavia, as duas variantes foram somadas, representando uma única variante padrão. Veja-se, a esse respeito, Cagliari (1981: 28-29) e Pontes (1973: 16).

${ }^{4}$ A motivação para esse teste deve-se à realização do item conversaiada. A dificuldade de transcrevê-lo na forma padrão (conversalhada é uma forma da qual não há notícia) evidenciou que a realização do sufixo composto -alhada restringe-se à forma não-padrão, exclusivamente, em alguns itens. Formulou-se, 
então, a hipótese de que, apesar de evitado por sua conotação pejorativa, esse sufixo, quando usado, realiza-se preferencialmente na forma não-padrão. Tal hipótese vai ao encontro da hipótese básica do trabalho, segundo a qual a propagação da vocalização, se houver, se dará através de itens de conotação pejorativa.

${ }^{5}$ A realização da variável em relação a cada um dos parâmetros analisados foi avaliada em cálculos percentuais. A relevância dos percentuais foi submetida ao teste do qui-quadrado (doravante $\mathrm{X}^{2}$ ), quando os mesmos sugeriam favorecimento do parâmetro visado. Lembrando que o objetivo do $\mathrm{X}^{2}$ é o de refutar a hipótese de que os resultados apresentados se devam ao acaso (hipótese nula), esclareço que no presente trabalho, o nível de significância adotado para esse teste foi .05 , grau de liberdade 1 ; portanto, todo resultado igual ou superior a 3. 84146 refuta a hipótese nula.

${ }^{6}$ É evidente que essa observação é condicionada por questões pragmáticas. Fatores culturais determinam o significado social de se ser velho.

${ }^{7}$ Essa conotação pejorativa do item reflete-se também no inquérito fonético de Rodrigues (1974): em duas circunstâncias (de um total de sete) nas quais poderia ter sido usado o item velho foi substituído pelas expressões senhor de idade e já foi moço.

${ }^{8}$ Em 1981, Labov propõe uma explicação capaz de conciliar o modelo Neogramático e o modelo da Difusão Lexical. Comparando certos processos de mudança com a pronúncia do 'short $a$ ' na Filadélfia, que se realiza como tenso, mas apresenta exceção em três palavras, nas quais se realiza como frouxo, Labov postula que a variação tenso - frouxo corresponde a uma mudança fonológica abstrata, que opera em níveis hierarquicamente mais altos do que aqueles em que operam regras como as de reajuste fonético. Apenas as mudanças desse tipo seriam implementadas lexicalmente. Se, por um lado, a explicação concilia a postulação dos dois modelos - o Neogramático e o da Difusão Lexical, por outro, instala uma nova polêmica, qual seja, pressupõe que determinados processos não se atualizam através de regras fonético-fonológicas, mas através de itens lexicais cuja realização não é previsível. Ao se fazer tal pressuposição, abre-se um espaço para especulações mais amplas que trazem em seu bojo o questionamento relativo à postulação de regras, mesmo para aqueles processos tidos como regulares. Pronunciando-se a esse respeito, Oliveira (1991 e 1992) procura demonstrar que todas as mudanças se dão por Difusão Lexical atualizadas por itens lexicais cujas características fonético-fonológicas determinam um maior ou menor grau de expansão da nova forma. Pressupõe sua explicação que aqueles processos que propiciam uma configuração absolutamente regular são aqueles cuja mudança foi atualizada em um contexto fonético favorecedor, que atua posteriormente à atualização da mudança. Os itens lexicais são, portanto, 
responsáveis pela atualização, o contexto fonético, responsável pela implementação, quando houver. Em 1994, Labov reconsidera a análise proposta em 1981 (supracitada) defendendo o princípio de que a mudança fonológica é passível de descrição orientada por regras que se submetem a princípios universais estabelecidos com base em traços abstratos. A atualização desses traços é relativa à configuração do sistema fonológico cujo dinamismo se expressa na variação observável por tempo e por língua. Ao propor tais princípios, Labov procura demonstrar que os processos de mudança analisados como de implementação pelo léxico podem ser descritos por regras que contenham as especificações dos itens lexicais, dentre suas condições de aplicação, conforme são estabelecidas as regras da fonologia lexical. Esse último pronunciamento de Labov pretende reafirmar a produtividade do modelo Neogramático.

${ }^{9}$ O volume 1 da Revista de Estudos da Linguagem é integralmente dedicado a relatos de pesquisas cujos resultados evidenciam ou sugerem a atuação do modelo da Difusão Lexical.

${ }^{10}$ Agradeço à profa. Márcia Cançado pela ajuda prestada na estruturação deste artigo. As falhas que, porventura, forem detectadas são, naturalmente, de minha inteira responsabilidade.

\section{REFERÊNCIAS BIBLIOGRÁFICAS}

CAGLIARI, L. C. Elementos de fonética do Português Brasileiro. Tese submetida como requisito parcial para a obtenção do título de Livre Docente, Universidade Estadual de Campinas. 1981.

CHEN, M. \& W. S-Y. WANG. Sound change: actuation and implementation. Language, v. 51, n.2, p.255-281, 1975

LABOV, W. Resolving the neogrammarian controversy. Language, v.57, n.2 p.267-308, 1981. 1994.

MADUREIRA, E. D. Sobre as condições de vocalização da lateral palatal no português. Dissertação de Mestrado, FALE/UFMG, Belo Horizonte, 1987.

. Difusão lexical e significado. Tese de doutoramento. UFMG (em preparo).

OLIVEIRA M. A. de. Variation and change in Brazilian Portuguese: the case of the liquids. Tese de Doutoramento. Universidade da Pensilvânia,1983.

The neogrammarian controversy revisited. International Journal of the Sociology of Language, vol.89, p.93-105. Berlim, 1991. 
OlIVEIRA M. A. de. Aspectos da difusão lexical. Revista de Estudos da Linguagem. Faculdade de Letras da UFMG, Belo Horizonte, p.31-41, 1992.

PONTES, E. Estrutura do verbo no Português coloquial. Petrópolis:Vozes, 1973.

RODRIGUES, A N. O dialeto caipira na região de Piracicaba. São Paulo: Ática, 1974. 